Utah State University

DigitalCommons@USU

$1-1-1979$

\title{
Late Time Barium Cloud Striations and Their Possible Relationship to Equatorial Spread F
}

Michael C. Kelley

K. D. Baker

J. C. Ulwick

Follow this and additional works at: https://digitalcommons.usu.edu/sdl_pubs

\section{Recommended Citation}

Kelley, Michael C.; Baker, K. D.; and Ulwick, J. C., "Late Time Barium Cloud Striations and Their Possible Relationship to Equatorial Spread F" (1979). Space Dynamics Lab Publications. Paper 64.

https://digitalcommons.usu.edu/sdl_pubs/64

This Article is brought to you for free and open access by the Space Dynamics Lab at DigitalCommons@USU. It has been accepted for inclusion in Space Dynamics Lab Publications by an authorized administrator of DigitalCommons@USU. For more information, please contact digitalcommons@usu.edu.

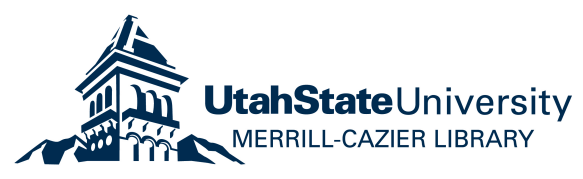




\title{
Late Time Barium Cloud Striations and Their Possible Relationship to Equatorial Spread $F$
}

\author{
Michael C. Kelley
}

Cornell University, Ihaca, New York 14853

\author{
K. D. BAKER
}

Utah State University, Logan, Utah 84322

\section{J. C. Ulwick}

\author{
Air Force Geophysics Laboratory, Hanscom Air Force Base, Massachusetts 01731
}

\begin{abstract}
An active experiment has been conducted in space that allows a test for the theory of nonlinear development of striations in large barium clouds. The results are in excellent agreement with a computer simulation of the $\mathrm{E} \times \mathrm{B}$ instability reported by Scannapieco et al. (1976). The power law irregularity spectrum predicted by the theory and verified by the experiment is shown here to be due to wave steepening and not to plasma turbulence. The barium cloud results are remarkably similar to bottomside equatorial spread $\vec{F}$. A possible role of the $\mathrm{E} \times \mathrm{B}$ instability in bottomside equatorial spread $F$ is discussed as a supplement to the Rayleigh-Taylor instability during the postsunset rise of the $F$ layer and during anomalous plasma uplifts which occur during geomagnetically active periods.
\end{abstract}

\section{INTRODUCTION}

Most experiments performed in space have been of the exploratory type rather than the active cause and effects methods typical of laboratory experiments. In this paper we report the interpretation of results of an active space experiment in order to test theoretical models for the development of a certain plasma instability and to determine whether natural plasma processes could be better understood based upon these experimental and theoretical studies. The experiment was part of a measurement program conducted for the Defense Nuclear Agency called Stress (Satellite Transmission Effects Simulation ), which had a primary objective of defining and characterizing the effects on satellite radio wave propagation through striated regions. Three large barium plasma clouds were deployed on three separate occasions to produce the striated regions. Our experiment required waiting sufficiently long for the development of striations to occur and firing instrumented sounding rockets through the structured clouds. In this way the fully developed nonlinear state of the plasma instability responsible for these structures could be studied.

The plasma instability generally accepted as the source for barium cloud striations in the mid-latitude ionosphere is the E $\times \mathbf{B}$ instability, first discussed by Martyn [1959]. The linear theory was developed by Simon [1963] for laboratory plasmas and adapted by Linson and Workman [1970] for ionospheric applications to barium clouds and tested in a computer simulation by Zabusky et al. [1973]. The linear process can be understood after a brief description of the initial development of a large barium cloud. Such clouds are a significant perturbation upon the ionospheric electrical circuit and polarize in such a way as to maintain divergence-free currents in the combined ionosphere/plasma cloud system. Since the cloud is a high-conductivity region, the internal electric field is smaller than the ambient (see the experimental results by Schutz et al., [1973]), and hence the plasma cloud drift velocity will be smallest at the center of the cloud. Material at the 'backside' of the cloud will thus catch up to the center, while material in the

Copyright (C) 1979 by the American Geophysical Union.

'frontside' (the direction of the $\mathrm{E} \times \mathbf{B} / B^{2}$ velocity, as measured in the frame of reference of the neutral wind) will move away from the central region. The backside will thus become very dense and develop a steep gradient in plasma density. It is this steep gradient which is unstable to the development of electrostatic waves.

As discussed by Linson and Workman [1970], the growth rate $\gamma$ is a function of wavelength but is usually normalized to $\gamma_{0}=E^{\prime} / B L \mathrm{~s}^{-1}$, where $L$ is the density gradient in the cloud and $E^{\prime}$ is the electric field in the neutral frame $\left(\mathrm{E}+\mathrm{V}_{n} \times \mathrm{B}\right)$. For typical values of $E^{\prime} / B$ equal to $100 \mathrm{~m} / \mathrm{s}$ and $L$ equal to 4 $\mathrm{km}, \gamma_{0}=2.5 \times 10^{-2} \mathrm{~s}$. Since the earliest striation measurements made in this rocket series were at 42 min after barium release, time was available for more than $50 e$ folds $\left(e^{\gamma t}\right)$ of any initial perturbations. Thus the clouds were clearly into the fully nonlinear regime, and comparison with linear theory is relevant only to the question of where the striations should first develop and not to their final amplitude or their distribution of amplitude with respect to wavelength (spectrum). In fact, it is very clear that linear theory is deceiving in this regard, since it predicts that the shortest wavelengths grow the fastest [Linson and Workman, 1970], whereas the observations discussed below and the nonlinear theoretical development by Scannapieco et al. [1976] show that the final state has more intensity at the longest wavelengths. A one-dimensional cloud was used in that theoretical study, but the coupling to the $E$ region was included, which makes it the most realistic simulation performed to date. We stress their results in our comparison between theory and experiment.

The next section presents a discussion of the data presentation. This is followed by a comparison with the nonlinear computational results. The results are then applied to the naturally occurring phenomenon of equatorial spread $F$.

\section{EXPERIMENT DESCRIPTION AND Data Presentation}

Details of the experiment and measurements have been presented by Baker and U/wick [1978], but a condensation is 

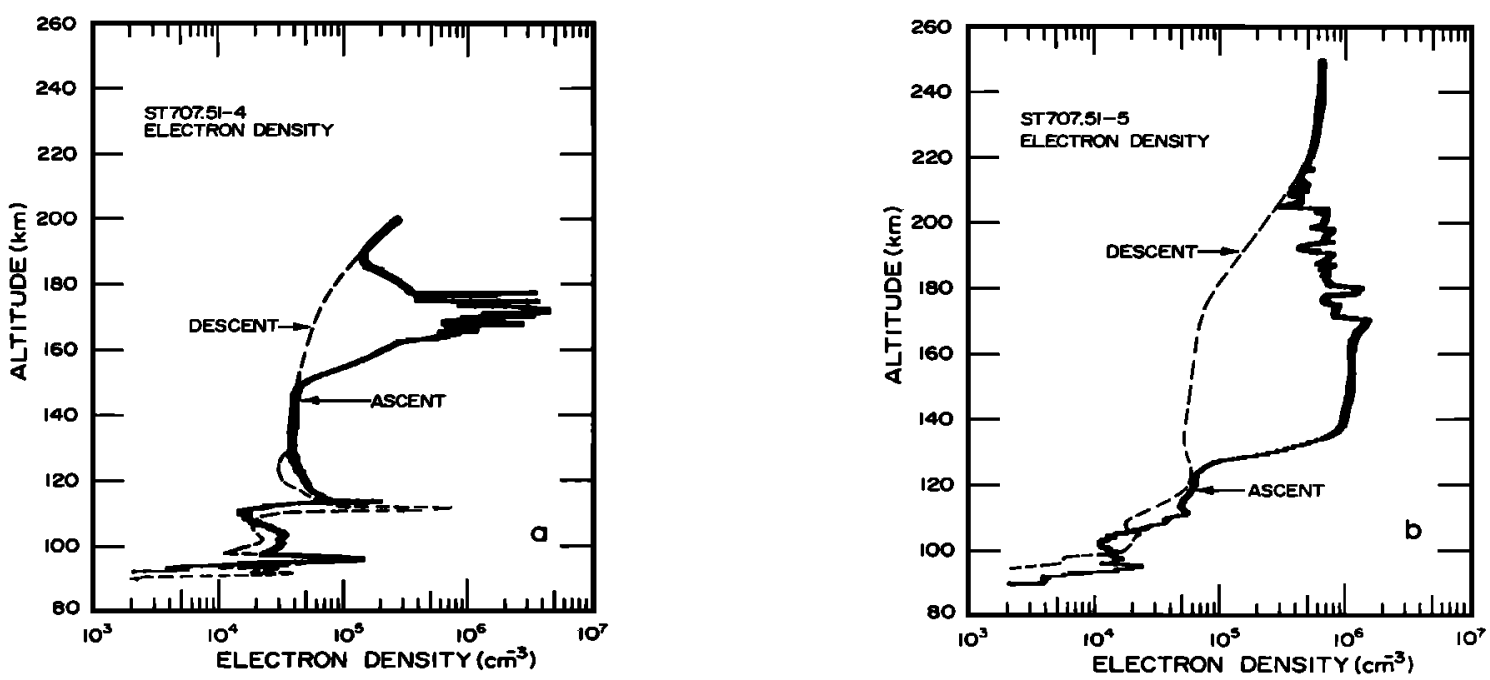

Fig. 1. Electron density profiles from probe rocket flights through two separate barium clouds on (a) March 13 (rocket 51-4) and (b) March 14 (rocket 51-5). The dashed curves are the measurements on rocket descent of the undisturbed $F$ region profile.

presented here for continuity. The investigations were conducted from Eglin Gulf Test Center, Florida, by utilizing rockets carrying barium and others carrying probes. The production of large plasma clouds was achieved by $48-\mathrm{kg}$ barium releases from rockets upon attaining altitudes of approximately $185 \mathrm{~km}$. The timing of the releases was such that the region was sunlit. Subsequently, as the barium vapor was ionized and developed striations, additional rocket-borne payloads, equipped with instrumentation to make fine-scale measurements of electron density, were launched in an effort to penetrate the striated portion of the ionized clouds. These probes provided profiles of the electron density and of the finescale structure $(>1 \mathrm{~m})$ internal to the clouds as well as measurements external to the clouds throughout the remainder of the flights.

The six rocket payloads used to probe the barium ion clouds were identical. The experimental section contained two electron density measuring instruments, a plasma frequency probe and a DC probe. Each of these probes utilized a portion of a 1$\mathrm{m}$ long, $6.35-\mathrm{cm}$-diameter nose spike as their sensing element in contact with the ionospheric plasma. Five of the six probe rocket flights operated successfully and penetrated portions of the last three barium clouds in the series. Striated regions of the second and third cloud were penetrated on two of the flights, and we emphasize these events here. From the paper by Baker and Ulwick [1978] we show these two results in Figures $1 a$ and $1 b$. The sharp peaks evident in the $E$ region (95 and 115 $\mathrm{km}$ ) in Figure $(a$ are sporadic $E$ layers not associated with this barium release. The probe entrance into the barium ion cloud showing the electron density enhancement above the ambient background and the electron density fuctuations due to probe penetration of the striated region are clear in both cases. The characterization of the structured region is different for the two events. These striated regions are the subject of our present study.

To facilitate the analysis of the fine-scale electron density variations the $F M$ analog telemetry channels were digitized at a rate of 10,000 samples per second. The time series of data were then detrended by fitting a third-order polynomial to the enhanced plasma region and dividing each data point by the value of the curve at that time. This generated a relative density data set $(\delta n / n)$ which was then Fourier analyzed and the power spectra plotted. Figure 2 shows the results of this analysis for the regions of striations of the two sets of data shown in Figures $\mathrm{I} a$ and $\mathrm{l} b$. The lowest measured frequency in the two plots was determined by the total length of time during which the striations were observed, 13 s for rocket 51-4 (Figure $1 a$ ) and $55.5 \mathrm{~s}$ for rocket $51-5$ (Figure $1 b$ ). The high-frequency limit was determined by the number of points averaged before the Fourier transform was constructed. Sixteen data samples were averaged for the data from cloud 2 and 80 samples averaged in the case of cloud 3. Except for some spikes at high frequency, both sets of data display a monotonic decreasing power with increasing frequency above $0.1 \mathrm{~Hz}$ in the case of rocket $51-4$ and above $0.06 \mathrm{~Hz}$ in the case of rocket $51-5$.

In the next section we interpret these spectra as being due to spatial variations in plasma density along the rocket trajectory. The results from rocket 51-5 are emphasized, owing to the longer time series of data available.

\section{COMPARISON OF EXPERIMENT AND THEORY}

The time domain analysis discussed above is not the best representation of the data, since the rocket velocity was great compared with the phase velocity of the waves associated with the $\mathbf{E} \times \mathbf{B}$ instability [Linson and Workman, 1970]. Also, the unstable waves have $\mathbf{k} \cdot \mathbf{B}=0$. Accordingly, we have converted the temporal data into spatial variations using the components of the rocket velocity perpendicular to the magnetic field, $V_{\perp}$. The set of relative density values from flight $51-5$, as determined from the detrending technique described above, is plotted in Figure 3 as a function of distance perpendicular to B. For a low phase velocity wave in the plasma frame the wave number $k$ is related to the frequency via the relation $k_{\perp}=2 \pi \mathrm{f} /$ $V_{\perp}$. The frequency power spectrum has been converted to a wave number spectrum and the results plotted as the solid circle data points in Figure 4, after averaging the data points over about a factor of 2 in wave number. The curve designated by crosses will be discussed later. Assuming a power law of the form $k^{-n}$, a linear least squares fit to the index yields $n=$ $-2.64 \pm 0.1$ in the range $4.42 \mathrm{~km}^{-1} \leq k \leq 283 \mathrm{~km}^{-1}$ and an in$\operatorname{dex} n=-2.52 \pm 0.01$ for the range $2.2 \mathrm{~km}^{-1} \leq k \leq 283 \mathrm{~km}^{-1}$. The $51-4$ data analyzed in this way shows a similar spectral index. Note that the index is quite sensitive to the choice of the wave number range. Also, the lowest wave number entries are sensitive to the detrending process.

The nonlinear theoretical calculations of the $\mathrm{E} \times \mathrm{B}$ instability presented by Scannapieco et al. [1976] are in remarkable agreement with these experimental results. They showed that 

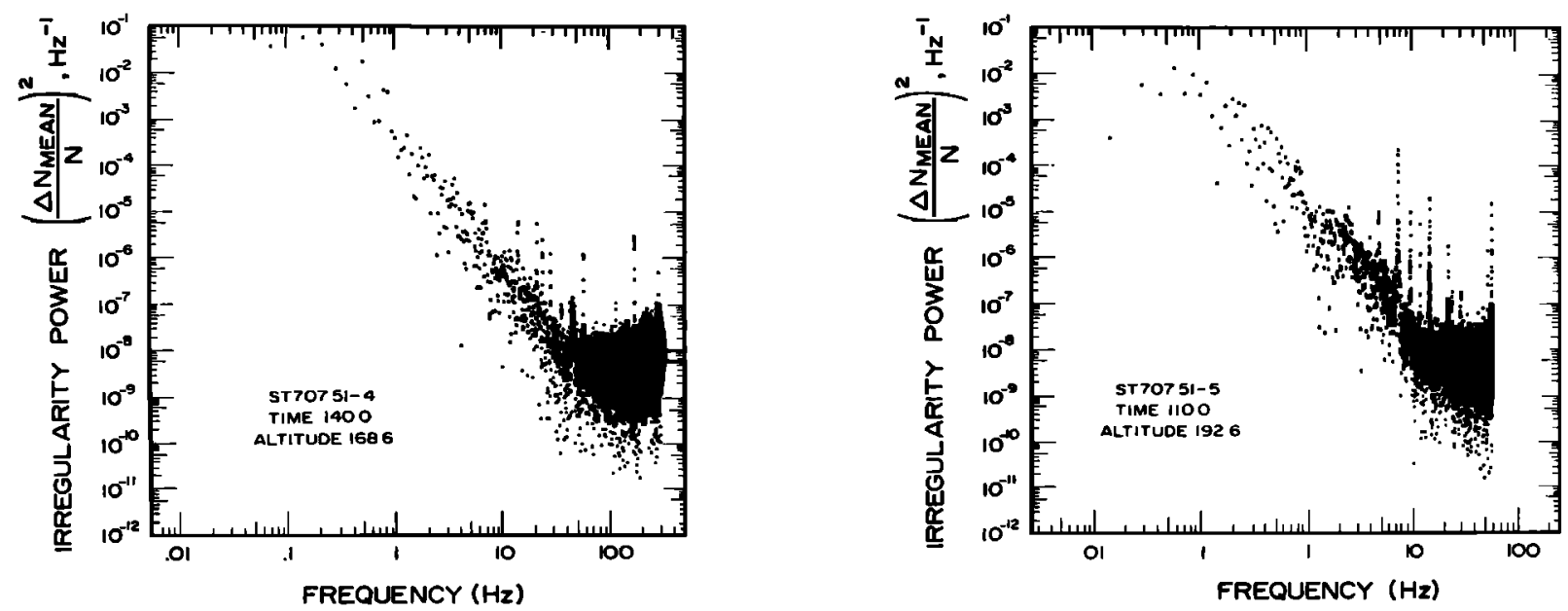

Fig. 2. Power spectral density of electron density irregularities measured with rocket probes flown through barium clouds on (left) March 13 and (right) March 14.

the cloud developes 'fingerlike' structures of enhanced plasma which are very similar to the plot in Figure 3. They have also calculated one-dimensional spectra from their results for simulated probe traversals parallel ( $x$ direction) and perpendicular ( $y$ direction) to the zero-order density gradient which can be compared with the probe results. They define a normalized wave number $k_{i}=k / k_{0}$, where $k_{0}=2 \pi / L$ and $i=x$ or $y$. For $k_{x}>3$ the power law at 1,520 s into the simulation was -3.3 , while for all $k_{x}>1$ the least square fit to a straight line at 1,520 s was -2.04 . At the same time, for all $k_{y}>1$ they found the index -1.95 . On the basis of the trajectory and neutral wind models, it seems likely that rocket $51-5$ was traveling at roughly a $45^{\circ}$ angle to the $x, y$ plane. For $L=4 \mathrm{~km}$ the portion of the barium data in Figure 4 above $k=4.4 \mathrm{~km}^{-1}$ corresponds to normalized wave numbers greater than 2.8 . The Figure 4 spectrum decreases at the smallest $k$ values plotted as does the $k_{x}$ spectrum computed by Scannapieco et al. The rocket data is thus consistent with the simulation and tends to be more closely matched to the $k_{x}$ run. In the next section the power law results are interpreted in more detail.

\section{INTERPRETATION OF THE RESULTS WITH APPLiCation to Equatorial SPREAd $F$}

\section{Wave Steepening Versus Plasma Turbulence} in the F Region Ionosphere

By far the most common spectrum reported by experimenters measuring plasma density flucutations in the $F$ region ionosphere is a power law with index near -2 . Rocket and satellite data obtained during equatorial spread $F$ conditions [Dyson et al., 1974; Kelley et al., 1976; Morse et al., 1977] as well as high-latitude irregularities [Dyson et al., 1974; Sagalyn et al., 1974] all indicated this form. It is well known that normal fluids develop power law spectral forms in turbulent flow, and it seems likely that plasmas behave in a similar manner in some cases. Another possibility for nonlinear development of neutral fluid and plasma waves, however, is wave steepening.

The difference between these two descriptions is illustrated in Figure 5. In the upper plot the detrended data from probe $51-5$ is plotted as was done previously in Figure 3. The time series of data was then Fourier analyzed and one complex amplitude and phase determined for each of the discrete frequencies. Then an arbitrary phase angle was added to each of these complex numbers by using a table of random numbers, and the data were transformed back into the time domain and plotted in the figure. The upper plot corresponds to no change in the phase angle, and hence it returns to the original data sample. The two other plots are from different random sets of phase angles. Since the phase angle does not affect the power spectrum, which is the absolute value of each of the complex numbers referred to above, the power spectrum of these three data streams is absolutely identical and, in fact, has already been plotted in Figure 4. We contend that the two lower plots are physically different from the true data and conform to the concept of a 'power law' irregularity spectrum as found in

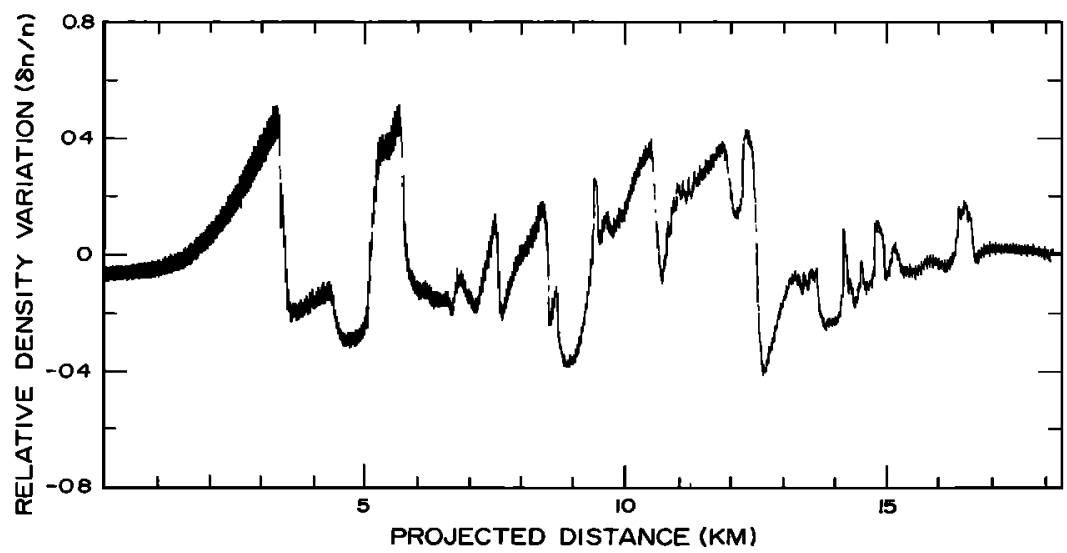

Fig. 3. Detrended data showing electron density variations $(\delta n / n)$ about the mean value for the region of striations from the probe results of rocket $51-4$, March 14 . 


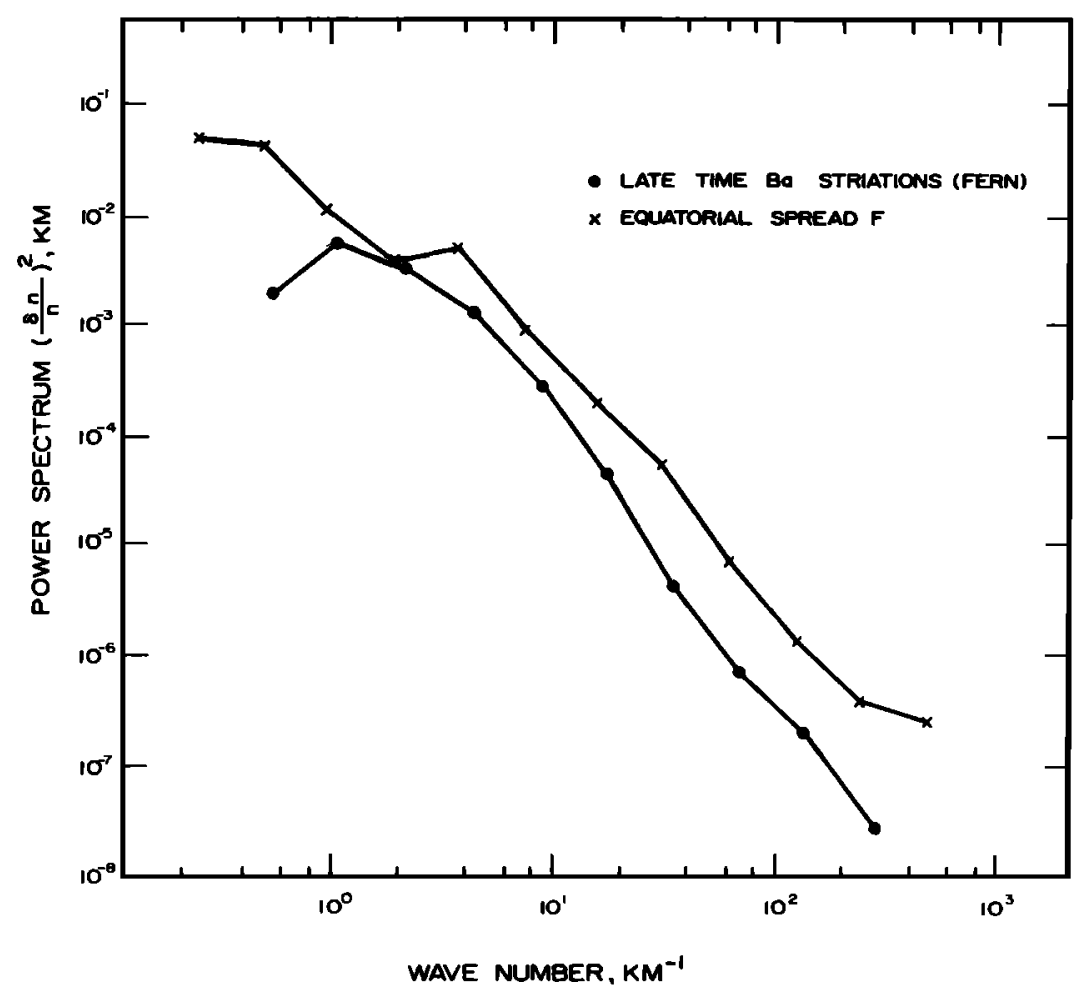

Fig. 4. Wave number power spectrum of the data shown in Figure 3. Also shown is a spectrum for a rocket flown into equatorial spread $F$ condition [Costa and Kelley, 1978].

fluid turbulence. The real data do not. The reason that a random phase factor accomplishes this transformation is that steepened structures require a certain coherence in the phase of the Fourier components to produce the sharp edges, whereas in turbulence this coherence does not exist. This type of analysis was first used by Costa and Kelley [1978], after a suggestion by $D$. T. Farley, to analyze naturally occurring equatorial spread $F$, which, as discussed below and as discussed earlier by Scannapieco et al. [1976] and Scannapieco and Ossakow [1976], is a phenomenon remarkably similar to late time barium cloud striations.

We thus conclude that the nonlinear evolution of the $\mathbf{E} \times \mathbf{B}$ instability and bottomside equatorial spread $F$ does not proceed by cascade processes such as occur in fluid turbulence but rather by steepening. Chaturvedi and Ossakow [1977] have developed an analytic theory for bottomside equatorial spread $F$ in which just such a wave steepening is predicted. Turbulent cascade does seem to occur in electrojet processes, albeit with a steeper power spectrum [McDonald et al., 1974, 1975; Ferch and Sudan, 1977] in magnetospheric convection [Kelley and Kintner, 1978], and has been suggested as a mechanism in topside equatorial spread $F$ [Kelley and Ott, 1978].

\section{Application to Equatorial Spread F}

Extensive rocket, satellite, and radio wave probing of the equatorial ionosphere is currently underway in an effort to understand the naturally occurring phenomena called equatorial spread $F$. Various types of 'spread $F$ ' occur worldwide and are caused by quite different processes. The equatorial type is one of the most interesting, since it occurs far from regions such as the auroral zone, where extraterrestrial effects complicate the theory, since it is readily accessible to experimental study and since it causes quite remarkable intense scintillation problems extending even into the gigahertz frequency range. Reviews of the rapidly changing status of equa- torial scintillation and spread $F$ theory have been published by Basu and Kelley [1977, 1979].

The connection between late time striation of barium clouds and equatorial spread $F$ is indicated in Figure 6, showing probe data obtained on a NASA rocket flight from Natal, Brazil. (To convert from seconds to kilometers, multiply by 2.) The rocket probes detected intense irregularities on the bottomside of the equatorial $F$ region [Costa and Kelley, 1978] which had structure very similar in appearance to the barium cloud data. In addition, both sets of data have nearly identical power spectra not only in spectral form but absolute value. This is shown in Figure 4, where the spread $F$ spectrum is plotted as the crosses. The spread $F$ spectral index was $-2.06 \pm 0.1$ in the range $1.91 \mathrm{~km}^{-1} \leq k \leq 244 \mathrm{~km}^{-1}$ and -2.29 \pm 0.1 in the range $3.82 \mathrm{~km}^{-1} \leq k \leq 244 \mathrm{~km}^{-1}$. As was mentioned above, the actual index is quite sensitive to the wave number range chosen.

The equatorial data were obtained below the peak in electron density which occurs at a relatively high altitude near the magnetic equator $(\sim 400 \mathrm{~km})$. This is the region where the spread $F$ disturbances originate and are first detected by ionosondes and backscatter radars. A remarkable feature of equatorial spread $F$, however, is that the structures are not confined to the bottomside but burrow through into the dense topside region where they have been detected as 'holes' or 'plumes' by satellite [McClure et al., 1977], rocket [Kelley et al., 1976], and radar [Woodman and $\mathrm{LaHoz}, 1976$ ] techniques. The high plasma density in this topside region coupled with the large layer thickness accessible to the irregularity formation process accounts for the intense VHF and gigahertz scintillations.

Indications of the upwelling process have encouraged several workers to investigate the collisional gravitational Rayleigh-Taylor instability due to the geometrical configuration on the bottomside of the equatorial $F$ peak, namely, $g$ (the acceleration due to gravity) antiparallel to $\nabla \mathrm{n}$ and both per- 

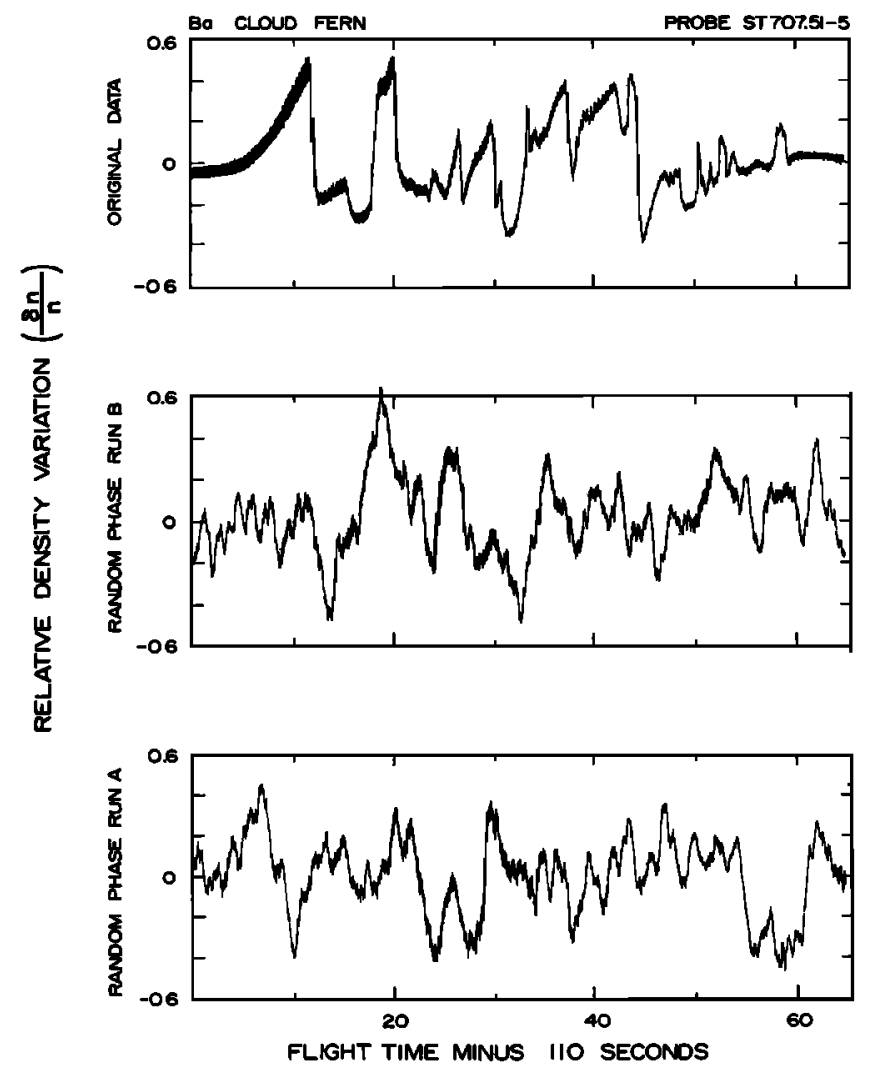

Fig. 5. Electron density variations $(\delta n / n)$ about the mean value. The upper plot is generated from the data from probe 51-5 shown in Figure 3, while the bottom two plots are generated by adding arbitrary phase angles to the Fourier components of the upper data and then reconstructing in the time domain.

pendicular to B. This condition is linearly unstable to the growth of flute mode waves. If $\mathbf{g}$ is parallel to $\nabla \mathbf{n}$ on the topside, for example, the waves are linearly damped. The process is almost identical in form to the backside instability of barium clouds. Under this model there is an interchange of high-density flux tubes downward and low-density regions upward. As was pointed out earlier, linear theory cannot be trusted in describing final states, and nonlinear effects become very important. As a finite plasma hole pushes up into the topside (see the computer simulation by Scannapieco and $O s$ sakow [1976]), the concept of a growth rate becomes meaningless and it is more appropriate to discuss the terminal velocity of such structures [Ott, 1978]. Note that on the topside the

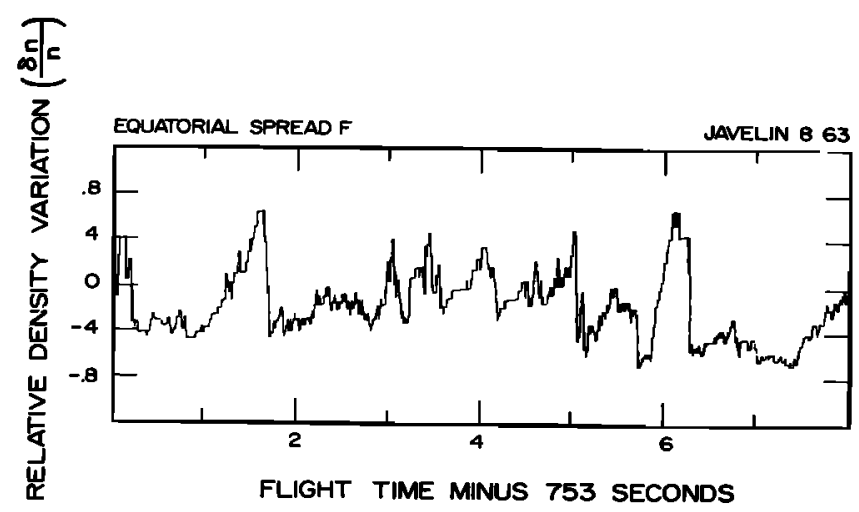

Fig. 6. Electron density variations from the rocket probe flown at $\mathrm{N}$ atal, Brazil, into an equatorial spread $F$ condition [Costa and Kelley, 1978].

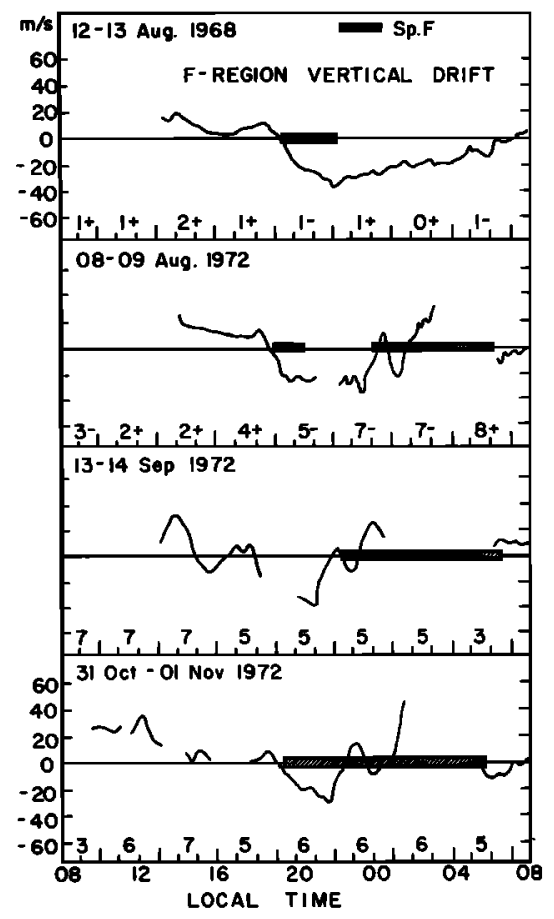

Fig. 7. Examples of the occurrence of spread $F$ compared with $F$ region vertical drift velocities over Jicamarca, Peru [from Fejer et al., 1976].

$\mathbf{g} \times \mathbf{B}$ current continues to flow, unlike Pedersen currents which require collisions, and hence can still supply charge to the edges of the bubbles causing the internal electric field to grow. Ion inertia may also be important at high altitudes [Ossakow and Chaturvedi. 1978].

Thus it seems that on the topside a gravitationally driven process is necessary. This success of gravitational theories on the topside, however, should not preclude other possibilities at low altitudes. We contend here that the same $\mathrm{E} \times \mathbf{B}$ instability process which causes late time striation in barium clouds contributes to the bottomside instability just after sunset and for a class of equatorial spread $F$ which occurs during geomagnetically active periods. At other times the gravitational process continues to operate and will cause growths of irregularities independent of, or initiated by, the Ex B process. Similar arguments have recently been advanced by Ossakow and Chaturvedi [1978] and Anderson and Haerendel [1979].

The geophysical conditions under which the $\mathrm{E} \times \mathrm{B}$ instability should enhance the growth rate of bottomside equatorial spread $F$ are those when there is a strong uplift of the $F$ region plasma. The key times alluded to above are both illustrated in Figure 7, reproduced from Fejer et al. [1976]. In this graph the vertical drift velocity of the $F$ region ionosphere over Jicamarca Peru is plotted along with an indication of times when equatorial spread $F$ occurred (cross-hatched areas) on several days. The pattern of vertical drift on August 12-13, 1968, is typical of the equatorial region. During the day the ionosphere drifts upward slowly. Near sunset there is often an enhanced upward velocity, seen this day at $1830 \mathrm{LT}$, which is followed by a reversal to downward drift, which lasts all night. Farley et al. [1970] have pointed out that initiation of equatorial spread $F$ often is correlated with this uplift in plasma. They rejected the $\mathbf{E} \times \mathbf{B}$ instability as the primary process [Reid, 1968], since once the ionosphere begins to move downward this process has a stabilizing influence.

We argue here that this electric field and its enhancement 


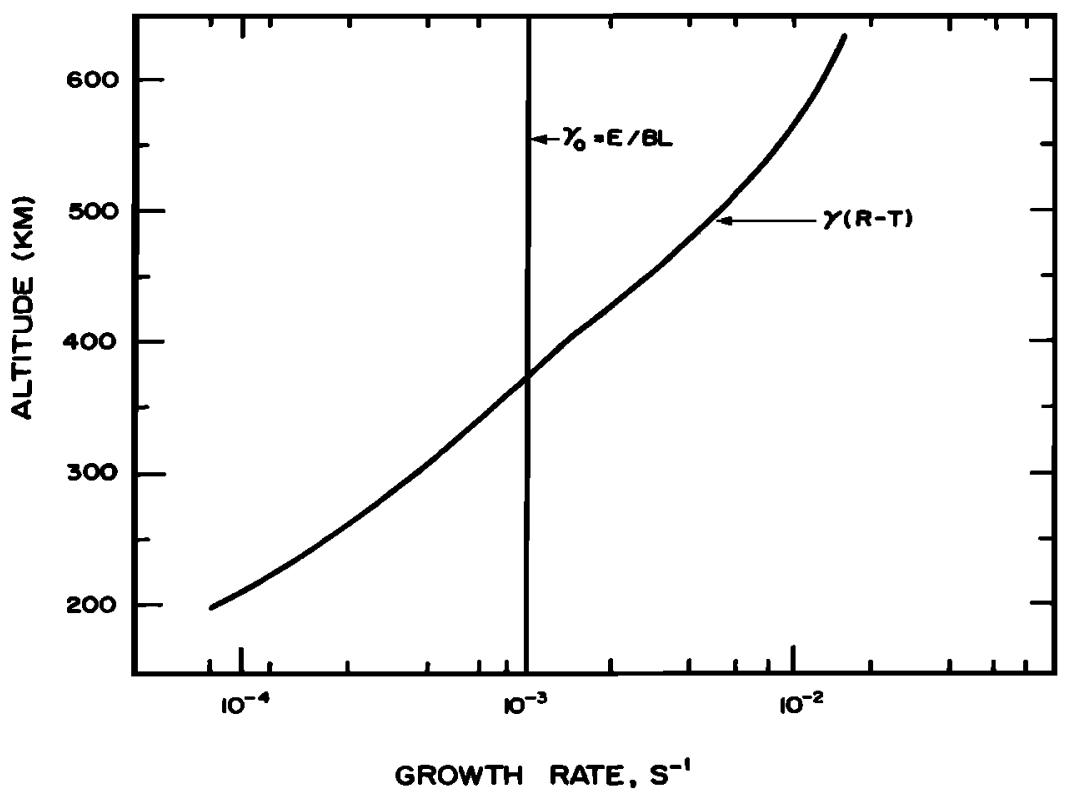

Fig. 8. Plot of linear growth rates for the Rayleigh-Taylor instability $(\gamma(\mathbf{R}-\mathbf{T}))$ and the $\mathrm{E} \times \mathbf{B}$ instability $\left(\gamma_{0}\right)$ for maximum solar conditions, a vertical drift velocity of $20 \mathrm{~m} / \mathrm{s}$, and a scale length of $20 \mathrm{~km}$.

near sunset play an important role in the initiation of equatorial spread $F$. Before pursuing this further we must point out that it is not just the increased electric field which controls the onset of equatorial spread $F$. When the sun sets in the $E$ region, recombination rapidly destroys the conductivity of that layer, which in turn allows the buildup of the $F$ layer perturbation electric fields. During the daytime such fields would be shorted out by the 'conducting end plates,' to use the vernacular of laboratory plasma physics. Recombination also eats away at the bottomside of the $F$ layer to create a steep vertically directed gradient on the bottomside. These three factors then play a role in the $\mathbf{E} \times \mathbf{B}$ instability of the equatorial $F$ layer: the absence of an $E$ region, the steep vertical gradient, and the eastward electric field.

In order to compare the relative importance of the collisional Rayleigh-Taylor instability with the $\mathbf{E} \times \mathbf{B}$ instability we have plotted the linear growth rates of these two processes in Figure 8 for the same conditions using the results in (2) of Hudson and Kennel [1975] for the former and Linson and Workman [1970] for the latter. In making these plots we have chosen sunspot maximum conditions [Johnson, 1960], a vertical drift velocity of $20 \mathrm{~m} / \mathrm{s}$ (see Figure 7), and a gradient scale length of $20 \mathrm{~km}$, which has been measured during equatorial spread $F$ conditions [Kelley et al., 1976]. Recombination damping is not included in either of these growth rates. We see that in the altitude range less than $380 \mathrm{~km}$ the $\mathbf{E} \times \mathbf{B}$ linear growth rate $\gamma_{0}$ exceeds the $\mathbf{R}$ ayleigh-Taylor growth rate. The rocket data indicate that the characteristic wavelength of bottomside structures is $\sim 5 \mathrm{~km}$, which for $L=20 \mathrm{~km}$, corresponds to $k L=8 \pi$.

The reinitiation of equatorial spread $F$ late in the evening on the other three nights plotted in Figure 7 may also be explained by this process, since an anomalous reversal of the vertical drift from negative to positive preceded this increase in irregularities. The particular change in equatorial electric field on August 8-9 1972, was correlated with a sharp increase in the auroral zone electric field [Gonzales et al., 1979]. Note that the timing error on both the electric field data and the spread $F$ onsets was about $10 \mathrm{~min}$.

It should be noted that Scannapieco et al. [1976] have pointed out the similarity between equatorial spread $F$ bubbles and the depleted regions of late time barium striations. The latter propagate toward the front of the barium cloud, since they have a larger $\mathbf{E} \times \mathbf{B}$ drift than the central portion which is loading down the flux tubes. The effect should be even more pronounced than the simulation shown [see Scannapieco et al. 1976, Figure 5], since in a one-dimensional cloud simulation the dense central portion cannot polarize and must continue to E $\times$ B drift with the ambient velocity. The two-dimensional Rayleigh-Taylor simulation by Scannapieco et al. [1976] indeed shows that a finite perturbation does work through to the topside in the form of low-density 'bubbles.'

Acknowledgments. It is a pleasure to acknowledge the efforts of the team that successfully carried out the difficult rocket measurements program under the direction of $\mathrm{L}$. Carl Howlett, Utah State University: Herb Mitchell, RD Associates, and Edward F. Allen, Space Data Corporation. The data reduction assistance of Niel Grossbard, Dennis Delorey, and associates at Boston-College is also gratefully recognized. These measurements were sponsored by the Defense Nuclear Agency as part of the Stress program, with Beverly Wayne Motal and Robert Bigoni serving as program managers.

The Editor thanks L. M. Linson and S. L. Ossakow for their assistance in evaluating this paper.

\section{REFERENCES}

Anderson, D. N., and G. Haerendel, The motions of depleted plasma regions in the equatorial ionosphere, J. Geophys. Res., 84, in press, 1979.

Baker, K. D., and J. C. Ulwick, Measurement of electron density structure in barium clouds, Geophys. Res., Lett., 5. 723, 1978.

Basu, S., and M. C. Kelley, Review of equatorial scintillation phenomena in light of recent developments in the theory and measurement of equatorial irregularities, J. Atmos. Terr. Phys., 39, 1229, 1977.

Basu, S., and M.C. Kelley, A review of recent studies of equatorial $F$ region irregularities and their impact on scintillation modeling, Radio Sci., in press, 1979.

Chaturvedi, P. K., and S. L. Ossakow, Nonlinear theory of the collisional Rayleigh-Taylor instability in equatorial spread $F$, Geophys. Res. Lett., 4, 558, 1977.

Costa, E., and M. C. Kelley, On the role of steepened structures and drift waves in equatorial spread $F, J$. Geophys. Res., 83, 4359, 1978.

Dyson, P. L., J. P. McClure, and W. B. Hanson, In situ measurements of the spectral characteristics of $F$ region ionospheric irregularities, J. Geophys. Res., 79, 1497, 1974. 
Farley, D. T., B. B. Balsley, R. F. Woodman, and J. P. McClure, Equatorial spread $F$ : Implications of VHF radar observations, $J$. Geophys. Res., 75, 7199, 1970.

Fejer, B. G., D. T. Farley, B. B. Balsley, and R. F. Woodman, Radar studies of anomalous velocity reversals in equatorial ionosphere, $J$. Geophys. Res., 81, 4621, 1976.

Ferch, R. L., and R. N. Sudan, Numerical simulation of the type II gradient drift irregularities in the equatorial electrojet, J. Geophys. Res., 82, 2283, 1977.

Gonzales, C. A., M. C. Kelley, B. G. Fejer, J. F. Vickrey, and R. F. Woodman, Equatorial electric fields during magnetically disturbed periods, 2, Implications of simultaneous auroral and equatorial measurements, submitted to J. Geophys. Res., 1979.

Hudson, M. K., and C. F. Kennel, Linear theory of spread $F, J$. Geophys. Res., 80, 4581, 1975.

Johnson, F. S., Satellite Environment Handbook, Stanford University Press, Palo Alto, Calif., 1960.

Kelley, M. C., and P. M. Kintner, Evidence for two-dimensional turbulence in a cosmic scale low plasma, Astrophys. J., 220, 339, 1978.

Kelley, M. C., and E. Ott, Two-dimensional turbulence in equatorial spread $F, J$. Geophys. Res., 83, 4369, 1978.

Kelley, M. C., G. A. Haerendel, B. B. Balsley, and F. S. Mozer, Evidence for a Rayleigh-Taylor type instability and upwelling of depleted density regions during equatorial spread $F$, Geophys. Res. Lett., 3. 448, 1976.

Linson, L. M., and J. B. Workman, Formation on striations in ionospheric plasma clouds, J. Geophys. Res., 75, 3211, 1970.

Martyn, D. F., Large-scale movements of ionization in the ionosphere, J. Geophys. Res., 64, 2178, 1959.

McClure, J. P., W. B. Hanson, and J. H. Hoffman, Plasma bubbles and irregularities in the equatorial ionosphere, J. Geophys. Res., 82, $2650,1977$.

McDonald, B. E., T. P. Coffey, S. L. Ossakow, and R. N. Sudan, Preliminary report of numerical simulation of type 2 irregularities in the equatorial electrojet, J. Geophys. Res., 79, 2551, 1974.

McDonald, B. E., T. D. Coffey, S. L. Ossakow, and R. N. Sudan,
Numerical studies of type 2 equatorial electrojet development, $R a-$ dio Sci. 10, 247, 1975.

Morse, F. A., B. C. Edgar, H. C. Koons, C. J. Rice, W. J. Heikkila, J. H. Hoffman, B. A. Tinsley, J. D. Winningham, A. B. Christensen, R. F. Woodman, J. Pomalaza, and N. R. Teixeira, Equion, an equatorial ionospheric irregularity experiment, J. Geophys. Res., 82, 578,1977

Ossakow, S. L., and P. K. Chaturvedi, Morphological studies of rising equatorial spread $F$ bubbles, $J$. Geophys. Res., 83, 2085, 1978.

Ott, E., Theory of Rayleigh-Taylor bubbles in the equatorial ionosphere, J. Geophys. Res., 83, 2066, 1978.

Reid, G. C., The formation of small-scale irregularities in the ionosphere, J. Geophys. Res., 73, 1627, 1968.

Sagalyn, R. C., M. Smiddy, and M. Ahmed, High-latitude irregularities in the topside ionosphere based on Isis 1 thermal probe data, $J$. Geophys. Res., 79, 4252, 1974.

Scannapieco, A. J., and S. L. Ossakow, Nonlinear equatorial spread $F$, Geophys. Res. Lett., 3, 451, 1976.

Scannapieco, A. J., S. L. Ossakow, S. R. Goldman, and J. M. Pierre, Plasma cloud late time striation spectra, J. Geophys. Res., 81, 937, 1976.

Schutz, S., G. J. Adams, and F. S. Mozer, Probe electric field measurements near a mid-latitude ionospheric barium release, J. Geophys. Res., 78, 6634, 1973.

Simon, A., Instability of a partially ionized plasma in crossed electric and magnetic fields, Phys. Fluids, 6. 382, 1963.

Woodman, R. F., and C. La Hoz, Radar observations of $F$ region equatorial irregularities, J. Geophys. Res., 81, 5447, 1976.

Zabusky, M. H., J. H. Doles III, and F. W. Perkins, Deformation and striation of plasma clouds in the ionosphere, 2, Numerical simulation of a nonlinear two-dimensional model, J. Geophys. Res., 78. $711,1973$.

(Received April 5, 1978;

revised July 28, 1978:

accepted December 11, 1978.) 